\title{
The Influence of Collective Moral Disengagement on Adolescents' Bystanding and Defending Behaviors of Peer Bullying: Moderating Effect of Peer Conformity
}

\author{
Ji-won Kim ${ }^{1}$, Sae-Young $\mathrm{Han}^{2}$ \\ M.A., Department of Child Development, Ewha Womans University, Seoul, Korea ${ }^{1}$ \\ Professor, Department of Child Development, Ewha Womans University, Seoul, Korea ${ }^{2}$ \\ 집단의 도덕적 이탈이 남녀 청소년의 또래괴롭힘 방관 및 방어 행동에 미치는 \\ 영향: 또래동조성의 조절효과를 중심으로 \\ 김지원 ${ }^{1}$, 한세영 ${ }^{2}$ \\ 이화여자대학교 아동학과 석사 ${ }^{1}$, 이화여자대학교 아동학과 교수 ${ }^{2}$
}

\begin{abstract}
Objectives: The purpose of this study was to examine if peer conformity controls the effect of adolescents' collective moral disengagement on bystanding and defending behaviors surrounding peer bullying.

Methods: A total of 314 middle school students (boys: 167, girls: 147) participated in this study. They responded to questions regarding collective moral disengagement, peer conformity, and bystanding and defending behaviors regarding peer bullying.

Results: Peer conformity failed to control the effect of collective moral disengagement on bystanding behavior. Further, the effect of collective moral disengagement on defending behavior was controlled by peer conformity.

Conclusion: This study highlights the importance of considering gender, collective moral disengagement, and peer conformity when seeking to increase defending behavior so as to reduce bystanding behavior in adolescents.
\end{abstract}

Keywords: collective moral disengagement, bystanding behavior, defending bahavior, peer conformity, peer bullying

\section{Introduction}

또래괴롭힘 연구들이 1970년대 초기에 들어서 시작되었으나 (H.-J. Chung, 2011), 연구의 관심사가 된지 오랜 시간이 흘렀 음에도 불구하고 여전히 우리사회에서는 심각한 수준의 또래 괴롭힘이 만연한 것으로 보고되고 있다(Ministry of Education, 2018; K. Song \& Lee, 2018). 또래괴롭힘이란 힘의 불균형에 의 해 대인 관계 내에서 일어나는 것으로, 한 학생이 한 명 또는

Corresponding Author: Sae-Young Han, Professor, Department of Child Development, Ewha Womans University, 52, Ewhayeodae-gil, Seodaemungu, Seoul, Korea

E-mail: evenhow@ewha.ac.kr
그 이상의 학생들에게 반복적·지속적·의도적으로 신체적, 정 신적인 상처나 고통을 주는 행위를 의미한다(Olweus, 1993). 또래괴롭힘 선행연구들에 따르면 또래괴롭힘은 괴롭힘 상 황에 존재하는 모든 학생들의 발달, 학교 적응 및 심리적 안 정 등에 부정적인 영향을 미치는 것으로 알려졌다(Hawker \& Boulton, 2000). 이에 따라 정부와 교육당국은 학교 폭력 예방 및 대책에 대한 법률을 제정하고 또래괴롭힘을 근절시키기 위 해 노력하고 있지만, 2018년 1차 학교폭력 실태조사 결과 여

(C)The Korean Association of Child Studies

This is an Open Access article distributed under the terms of the Creative Commons Attribution Non-Commercial License (http:// creativecommons.org/licenses/by-nc/4.0) which permits unrestricted noncommercial use, distribution, and reproduction in any medium, provided the original work is properly cited. 
전히 괴롭힘 피해응답률은 증가하였다(Ministry of Education, 2018). 이러한 현실은 또래괴롭힘을 이해하고 예방하기 위해 서는 기존과는 다른 접근이 필요함을 시사한다.

또래괴롭힘은 크게 두 가지로 관점에서 연구되어왔다. 하 나는 가해자와 피해자에 주안점을 두는 것이고, 다른 하나는 또래괴롭힘이 발생하는 사회 집단이나 문화에 초점을 두는 것이다(J. Kim \& Kim, 2000). 또래괴롭힘 예방 및 중재를 위 한 초기의 연구들은 전자의 관점으로 이들의 특성을 밝히고 자 하였다. 그러나 괴롭힘이 사회적 관계 내에서 발생되며 집 단 내의 상호작용을 통해 강화된다는 점(Griffin \& Gross, 2004; Salmivalli, Lagerspetz, BjÖrkqvist, Österman, \& Kaukiainen, 1996; Sutton \& Smith, 1999)을 근거로, 또래괴롭힘을 가해와 피해의 한 쌍으로만 구성된 배타적인 관계로 파악하기보다 주 변 또래들의 역할 행동까지 포괄하여 총체적인 시각으로 조망 해야 할 필요성이 제시되었다.

또래괴롭힘 상황에서 가해자와 피해자를 제외한 주변인 들의 역할은 괴롭힘을 목격한 후에 어떠한 반응을 보이는지 에 따라 방관자, 방어자, 가해동조자로 구분할 수 있다(Nam \& Hong, 2015; Salmivalli et al., 1996). 또래괴롭힘 주변인 역할 행 동과 관련한 초기의 연구들은 괴롭힘을 일으키는데 적극적으 로 기여하는 가해동조 행동을 가해 행동과 함께 연구하여, 괴 롭힘을 예방하고자 하였다(Y. Cho \& Chung, 2009). 그러나 국 외 연구에서 방관이나 방어 행동에 대한 관심이 시작되었고, 최근 들어서는 국내 연구에서도 가해동조 행동뿐 아니라 방관 행동과 방어 행동에 대한 관심이 증가하기 시작하였다.

또래괴롭힘 주변인 역할 행동 중 가장 빈도가 높은 방 관 행동과 두 번째로 많이 나타났던 방어 행동(Ministry of Education, 2017, 2018)은 가해동조 행동과는 달리 괴롭힘 행 동을 하지 않는 집단에 속한다. 이들은 괴롭힘 상황에서 공격 적인 행동을 하지 않는다는 점에서 유사하지만, 친사회적이며 도덕적인 행동을 하는지 여부에 있어서는 차이를 나타낸다. 특히 방관 행동의 경우 또래괴롭힘 주변인 역할 행동 중 방어 행동으로 변화할 가능성도 나타났지만, 가해동조자로 전환되 는 양상 또한 다른 역할 행동보다 상대적으로 높게 나타났다 (Seo, 2013). 따라서 방관자가 가해동조자로 변하지 않도록 방 관 및 방어 행동을 집중적으로 살펴보아, 방어 행동을 증진시 키고 방관 행동을 감소시킬 만한 요인을 탐색하는 것은 또래 괴롭힘 예방 및 개입의 기초 작업이 될 것으로 예상된다. 국외 에서는 방관 및 방어 행동에 초점을 둔 연구들이 다수 존재하 지만(Caroline \& Bukowski, 2015; Gini, Albiero, Benelli, \& Altoe, 2008; Nickerson, Mele, \& Princiotta, 2008; Pozzoli \& Gini, 2010;
Thornberg, Wänström, \& Pozzoli, 2017), 국내에서는 가해 및 가 해동조 행동에 대한 연구에 비해 상대적으로 부족한 실정이 다. 따라서 본 연구에서는 방관 행동과 방어 행동을 함께 살펴 보아 관련 요인을 파악해보고자 하였다.

또래괴롭힘 방관 및 방어 행동과 관련한 요인으로 공감, 폭력에 대한 허용적 태도, 자기효능감, 공격성, 자기통제 등 이 있으나 최근에는 도덕적 인지 요인인 도덕적 이탈에 대 한 연구가 주목받고 진행되고 있다(Bang, 2018). 국내외의 여 러 선행 연구들에 따르면 도덕적 이탈은 피해자를 방관하 는 행동(Caroline \& Bukowski, 2015; Gini, Pozzoli, \& Bussey, 2015; Pozzoli, Gini, \& Vieno, 2012; Thornberg et al., 2017)과 는 정적 관계, 피해자를 보호하는 방어 행동(Almeida, Correia, \& Marinho, 2010; Caroline \& Bukowski, 2015; Mazzone, Camodeca, \& Salmivalli, 2016; Pozzoli et al., 2015; Pozzoli, Gini, \& Thornberg, 2016; J.-Y. Song \& Oh, 2016; Thornberg et al., 2017)과는 부적 관계를 나타냈다. 즉, 개인이 도덕적으로 많이 이탈되어 있을수록 또래괴롭힘 상황에서 피해자를 방어해주 기보다는 모른 척 하는 방관 행동을 많이 하기 쉽다는 것이다. 이러한 도덕적 이탈의 영향은 개인이 가지고 있는 도덕적 인 지특성의 하나인 개인내적 요인의 작용으로 이해할 수 있다.

한편, 이러한 개인내적 요인인 도덕적 이탈의 수준에 따라 서 개인이 방어나 방관행동을 표현할 수 있을 것인지, 또는 개 인이 행동을 수행하도록 동기화시키는 또 다른 사회적인 요인 이 있는지에 대한 탐색이 필요하다. 선행 연구에 따르면 또래 괴롭힘 상황에서 주변인들은 피해 학생을 방어해주어야 한다 는 생각을 할지라도 다른 친구들이 자신의 행동을 부정적으 로 바라볼 것으로 예상하여 소극적으로 행동한다(Sandstrom $\&$ Bartini, 2010). 이는 다수의 아이들이 또래괴롭힘이 바람직 하지 않고 수용될 수 없는 행동이라 생각하면서도(Boulton, Trueman, \& Flemington, 2002) 실제로 개입하지 않는 현상 (O'Connell, Pepler, \& Craig, 1999)을 의미하는 '주변인 딜레마' 로 설명이 가능하다. 주변인 딜레마는 피해자를 돕는 행동에 필요한 개인적인 특성이 확보되어도 주변 또래의 태도와 같은 상황적인 요인으로 인해(Cowie, 2014) 또래괴롭힘에 적극적 으로 개입하지 못하고 내적 갈등을 경험하는 현상으로 설명되 기도 한다. 따라서 개인의 도덕적 이탈의 정도로 주변인의 역 할 행동을 예측하는 것은 집단적인 맥락 속에서 주변을 의식 한 결과 적극적으로 괴롭힘 상황을 방관하고 방어하지 못하는 학생들에 대해서는 고려하지 못할 수 있다.

대부분의 도덕적 이탈에 대한 선행연구들은 전형적으로 집 단 도덕성을 고려하지 않고 개인적인 도덕적 인지에만 초점을 
맞추고 있다는 한계를 지닌다(Pozzoli et al., 2015). 이를 보완하 기 위해 국외에서는 개인이 속한 집단이 얼마나 도덕적으로 이탈되었는지를 의미하는 집단의 도덕적 이탈(collective moral disengagement)이라는 개념으로 측정되기 시작하였다. 집단의 도덕적 이탈은 개인이 속한 사회적 집단 내에서 공유되는 비 도덕적인 행동을 정당화하는 신념으로(Pozzoli et al., 2015), 상 호적이며 동등한 집단의 역동으로부터 발생하는 집단 수준의 가치를 의미한다. 이러한 선행연구가 제시한 개념을 적용하 여 본 연구에서는 집단의 도덕적 이탈을 아동기부터 청소년기 까지 가장 중요한 사회적 맥락 중 하나로 보고되는 개인이 속 한 '학급(class)'의 구성원들이 얼마나 도덕적으로 이탈되어있 는지에 대한 개인의 인지 또는 지각으로 정의한다. 대부분의 괴롭힘은 같은 학급에 소속된 또래들 간에 발생하기 때문에 (Ministry of Education, 2018; Salmivalli et al., 1996), 학급 구성 원들이 도덕적으로 얼마나 이탈되었다고 개인이 인지하는지 에 따라 괴롭힘 상황에서 주변인으로서의 개인의 역할 행동의 방향이 결정될 것으로 예상할 수 있다.

한편, 이러한 집단의 특성으로부터 얼마나 크게 영향을 받 는가는 개인이 가진 또래집단에 대한 동조성향과도 관계가 있 다. 또래동조성은 집단의 가치나 행동 등이 개인의 신념과 일 치하지 않을 때에도 또래집단에 소속되고자 또래집단으로부 터 승인되는 행동 양상을 선택하는 경향성을 일컫는다(Santor, Messervey, \& Kusumakar, 2000). 이러한 또래동조성이 높은 청 소년은 자신의 도덕추론에 대한 확신을 가지고 있더라도 집단 의 행동을 따르는 경향이 있지만(H.-L. Cho, 2002; B.-E. Kim $\&$ Choi, 2016), 또래동조성이 낮은 청소년은 자신의 사고와 정 서를 적절하게 통제할 수 있어 또래집단에 동조를 해야 하는 상황일지라도 올바른 도덕행동을 선택할 가능성이 높다(B.-E. $\mathrm{Kim} \&$ Choi, 2016). 또한 실제 국내의 선행연구들을 살펴보면, 또래동조성은 또래괴롭힘의 방관 행동에 유의한 정적 영향을 미쳤고(Y. Cho \& Chung, 2009; J.-H. Chung \& Oh, 2018; Jeong $\&$ Lee, 2016), 방어 행동에는 부적인 영향을 미친다고 보고되 었다(J.-H. Chung \& Oh, 2018; Jeong \& Lee, 2016; J.-Y. Song \& $\mathrm{Oh}, 2016)$. 이러한 선행연구들을 근거로, 또래동조성이 높은 학생은 학급 집단의 도덕적 이탈의 정도를 높게 지각할 경우 또래괴롭힘 상황에서의 다수의 집단원의 행동을 따라 방관 행 동을 할 가능성이 높고, 또래동조성이 낮은 학생은 학급 집단 의 도덕적 이탈을 높게 지각하여도 올바른 도덕적 행동을 선 택하여 방어 행동을 할 확률이 높을 것임을 예상해볼 수 있다. 즉, 또래동조성의 정도에 따라 집단의 도덕적 이탈이 또래괴 롭힘 방관 및 방어 행동에 미치는 영향력이 증폭 또는 완화될
수 있을 것으로 예상된다.

종합하면, 또래괴롭힘 방관 및 방어 행동의 선행 변인에 대 한 연구들은 대부분 개인적인 특성에 주목하였으나, 도움 행 동에 필요한 개인적인 특성이 확보되어도 주변인 딜레마로 인 해 괴롭힘에 개입하지 못하는 경우를 설명하지 못한다는 한계 를 지닌다. 이는 또래괴롭힘 방관 및 방어 행동이 개인적인 특 성에 의해서만 결정되는 것이 아니라 주변 맥락적인 특성 또 한 개입할 가능성을 시사한다. 따라서 본 연구에서는 또래괴 롭힘 방관 및 방어 행동을 예측하는 인지적 맥락 특성으로 학 급 집단의 도덕적 이탈의 역할을 살피고, 청소년기 발달적 특 성이자 친가해적 행동의 유력한 예측 변인(Y. Cho \& Chung, 2009; J.-H. Chung \& Oh, 2018; B.-E. Kim \& Choi, 2016; B. K. Kim \& Han, 2016)인 개인의 또래동조성이 집단의 도덕 적 이탈과 상호작용하여 또래괴롭힘 방관 및 방어 행동을 어 떻게 다르게 예측하는지 살펴보고자 한다. 이에 더하여 집단 의 도덕적 이탈(Gini et al., 2015; Kimberley \& Bussey, 2017), 또 래동조성(Jeong \& Lee, 2016), 또래괴롭힘 방관 및 방어 행동 (Caroline \& Bukowski, 2015; Mazzone et al., 2016; Pozzoli et al., 2015; H. Sim, 2008) 모두 남학생이 여학생보다 더 높게 나타 난 바가 있으므로 성을 구분하여 조절효과를 살펴보았다. 본 연구 결과는 청소년을 대상으로 학교 현장 및 또래괴롭힘 예 방 프로그램과 상담의 기초자료로 활용될 수 있을 것으로 예 상된다.

\section{연구문제 1}

집단의 도덕적 이탈이 남자 청소년의 또래괴롭힘 방관 및 방어 행동에 미치는 영향을 또래동조성이 조절하는가?

\section{연구문제 2}

집단의 도덕적 이탈이 여자 청소년의 또래괴롭힘 방관 및 방어 행동에 미치는 영향을 또래동조성이 조절하는가?

\section{Methods}

\section{연구대상}

본 연구의 대상은 경기도와 인천광역시에 소재한 4 곳의 중학 교에 재학 중인 1-3학년의 남녀 청소년 314명이다. 연구 대상 을 중학생으로 정한 이유는 도덕적 이탈이 학령기보다 청소 년기에 더 나타나기 시작하며(Mazzone et al., 2016), 또래동조 
성도 약 14-15세경에 최고조에 달하게 되어 청소년 후기로 갈 수록 자율성이 발달하여 줄어들기 때문이다(Jang, 2009). 또 한 초, 중, 고등학생을 대상으로 실시한 2018년 1차 학교폭 력 실태조사에서 같은 학교 같은 반 학생에 의해 피해를 입 은 비율이 중학교 $(50.1 \%)$ 에서 가장 높게 나타났다(Ministry of Education, 2018). 이러한 점을 고려하여 본 연구에서는 중학 교 1학년에서 3학년에 재학 중인 남녀 중학생들을 연구대상 으로 선정하였다. 연구대상의 사회인구학적 특성을 살펴보면, 성은 남학생 167명(53.2\%)과 여학생 147명(46.8\%), 학년은 1 학년 110명(35.0\%), 2학년 116명(36.9\%), 3학년 88명(28.0\%) 으로 총 314 명이었다. 남녀 청소년의 평균 연령은 13.97 ( $S D=$ 0.82)세였다.

\section{연구도구}

본 연구에서 집단의 도덕적 이탈, 또래동조성, 또래괴롭힘 방 관 및 방어 행동은 청소년의 보고로 응답된 질문지를 통해 측 정되었다.

\section{또래괴롭힘 방관 및 방어 행동}

본 연구에서는 또래괴롭힘 방관 및 방어 행동을 측정하기 위하 여 Salmivalli 등(1996)이 개발한 참여자 역할 질문지(Participant Role Questionnaire [PRQ])를 Seo (2008)가 수정하고 보완한 척 도를 사용하였다. 원척도에서는 주변인 역할행동을 조력, 강 화, 방어, 방관으로 구분하였으나 Seo (2008)는 조력과 강화를 가해동조로 통합하여 방관, 방어, 가해동조의 세 역할 행동으 로 범주화하였다.

본 척도는 방관 행동(6문항), 방어 행동(6문항), 가해동조 행동(6문항)의 세 하위요인, 총 18 문항으로 구성되어있다. 그 러나 앞서 언급하였듯이, 본 연구에서는 방관 및 방어 행동에 초점을 두어 방어 행동을 증진시키고 방관 행동을 감소시킬 만한 요인을 탐색하고자 하여 방관 행동과 방어 행동 문항들 만을 활용하였다. 방관 행동은 “또래괴롭힘 상황을 보아도 평 소대로 내 할 일을 한다.", 방어 행동은 "괴롭힘 당하는 아이에 게 힘과 용기를 준다.”와 같은 질문들이 포함되어 있다. 각 문 항은 '지난 9월부터 현재까지'의 자신의 행동을 전혀 그렇지 않다(1점)에서 매우 그렇다(4점)의 4점 Likert식 척도를 통하여 평가되었다. 점수가 높을수록 해당 역할의 행동 정도가 높은 것을 의미한다. 본 연구에서의 내적합치도(Cronbach's $\alpha$ )는 방 관 행동 .92 , 방어 행동 .83 이었다.

\section{집단의 도덕적 이탈}

집단의 도덕적 이탈은 Bandura, Barbarnelli, Caprara와 Pastorelli (1996)가 도덕적 이탈 척도(Mechanisms of Moral Disengagement Scale [MMDS])의 30 문항을 기반으로 탐색적 요인 분석을 실시 하여 Gini, Powwoli와 Bussey (2014)가 수정한 학급 집단의 도덕 적 이탈(Class Collective Moral Disengagement [CMD])을 번역 후 역번역 과정을 거쳐 사용하였다. 이는 연구자가 번역한 후, 한국 어와 영어 모두에 능통한(bilingual) 1 인이 역번역 하였고 그 내용 을 다시 본 연구자와 아동학 전공자가 확인하는 과정을 거쳤다.

본 척도는 도덕적 정당화(3문항), 완곡한 명명(1문항), 유리 한 비교(2문항), 책임 전가(1문항), 책임 분산(1문항), 결과 왜 곡(4문항), 비인간화(4문항), 비난의 귀인(1문항)의 8 가지 하 위요인으로 이루어져있다(총 17문항). 각 문항에는 “우리 반 의 ( )\%는 …라고 생각한다.”로 구성되어 학급 내의 학생들이 이러한 하위문항에 대해 어떻게 생각하고 있는지 답할 수 있 게 되어있다. 각 하위요인 별 문항들을 살펴보면, 도덕적 정 당화는 “친구를 보호하기 위해 싸움하는 것은 괜찮다.”, 완곡 한 명명은 "얄미운 아이를 때리는 것은 그 아이가 잘못을 깨 닫도록 하는 것이다.”, 유리한 비교는 “다른 아이를 때리는 것 에 비하면, 깔보며 욕하는 것은 큰 문제가 아니다.”, 책임 전가 는 "아이들이 나쁜 행동을 하는 것은 선생님의 잘못이다.", 책 임분산은 “주위 친구들 따라 나쁜 말을 쓰는 아이를 비난할 수 없다.", 결과 왜곡은 "다른 아이를 놀리는 것은 그 아이에게 반 드시 상처가 되지는 않는다.", 비인간화는 "짐승취급을 당해 도 마땅한 사람들이 있다.”, 비난에 대한 귀인은 “또래들에게 괴롭힘을 당하는 아이들은 대개 그럴만한 행동을 한다.”와 같 은 문항들로 구성되어있다. 각 문항에는 원척도와 같이 $0 \%(1$ 점), $25 \%$ (2점), $50 \%$ (3점), $75 \%$ (4점), $100 \%$ (5점)의 5점 Likert식 척도를 통하여 평가되었다.

본 척도는 8 개의 하위요인으로 구성되어 있으나, 단일요인 으로도 해석이 가능하며(Gini et al., 2014), 여러 선행연구들(Gini et al., 2015; Kollerova, Soukup, \& Gini, 2018; Thornberg et al., 2017)에서도 단일요인으로 사용하기에 무리가 없음이 입증되 었다. 따라서 본 연구에서도 집단의 도덕적 이탈을 단일요인으 로 사용하였다. 점수가 높을수록 집단의 도덕적 이탈의 정도가 큼을 의미하며 문항 간 내적합치도(Cronbach's $\alpha$ )는 .90이었다.

\section{또래동조성}

본 연구에서는 청소년의 또래동조성을 측정하기 위하여 
Berndt (1979)가 개발한 또래동조성 척도(Peer Conformity Inventory [PCI])를 Y. Cho와 Chung (2009)이 수정 및 보완한 척도를 J.-H. Chung과 Oh (2018)가 일부 수정한 척도를 사용 하였다. 본 척도는 중립적 동조성(7문항), 반사회적 동조성(6 문항)으로 총 13 문항으로 구성되어있다. 중립적 동조성은 “영 화를 보고 싶지만 친구들이 노래방에 가자고 할 때 어떻게 할 것인가?”, 반사회적 동조성은 "친구들이 신호를 무시하고 횡 단보도를 건너자고 할 때 어떻게 할 것인가?“와 같은 질문들이 포함되어있다. 각 문항은 절대 하지 않는다(1점), 하지 않는 편 이다(2점), 하는 편이다(3점), 확실히 한다(4점)의 4점 Likert식 척도를 통하여 평가되었다.

본 척도는 2 개의 하위요인으로 구성되어 있으나, 단일요인 으로도 해석이 가능하며(Berndt, 1979), 선행연구(J.-H. Chung $\& \mathrm{Oh}, 2018)$ 에서도 단일요인으로 사용하기에 무리가 없음 이 입증되었다. 따라서 본 연구에서는 13 문항을 총합하여 평 균한 값을 분석에 사용하였다. 점수가 높을수록 또래동조성 의 정도가 큼을 의미하며 문항 간 내적합치도(Cronbach's $\alpha$ )는 .83 이었다.

\section{연구절차}

본 연구의 자료는 경기도, 인천광역시에 소재한 4 곳의 남녀 중 학생을 대상으로 실시되었다. 2018년 12월 중 경기도에 위치 한 중학교에 협조를 요청하고 하루에 걸쳐 설문지를 배부하고 자료를 수집하였다. 설문을 시작하기 전에 각 담임교사에게 설문지 배부 방법 과 응답 시 유의사항을 설명하였고, 각 학급 의 담임교사들이 학생들에게 설문지를 배부하고 직접 회수하 였다. 배부된 453 부 중 314 부가 회수되어 $83.9 \%$ 의 회수율을 보였다. 분석 결과, 모든 변인의 왜도와 첨도의 절대값이 .11 $\sim .95$ 로 각각 3 과 10 미만으로 나타나 정규성이 확보되어 최종 분석에 314 부를 사용하였다.

\section{자료분석}

수집된 자료는 SPSS 21.0 (IBM Co., Armonk, NY)을 사용하 여 분석하였다. 먼저, 연구 대상의 사회인구학적 특성을 살펴 보기 위하여 빈도분석을 통해 각 변인의 빈도와 백분율(\%) 을 산출하였다. 둘째, 조사도구의 신뢰도를 확인하기 위해 Cronbach's $\alpha$ 값을 살펴보았다. 셋째, 각 변인들 간의 상관관계 를 확인하기 위해서 Pearson의 적률상관계수를 산출하였다. 넷 째, 집단의 도덕적 이탈이 또래괴롭힘 방관 및 방어 행동에 미
치는 영향을 또래동조성이 조절하는지에 관한 연구모형을 검 증하기 위해 Baron과 Kenny (1986)가 제안한 방법을 위계적 회 귀 분석을 통해 실시하였다. 조절효과가 유의미한 경우 Aiken 과 West (1991)의 제안에 따라 1차적으로 또래동조성을 중심 화한 평균을 중심으로 $\pm 1 S D$ (상, 하)집단으로 나눈 후, 각 집단 의 회귀식의 기울기에 대한 유의도를 검증하였다. 그러나 조 절효과가 유의미하게 나타났지만 각 집단 모두 회귀식의 기울 기가 유의미하지 않을 경우에는 추가적으로 $\pm 2 S D$ (상, 하)집 단으로 나눈 후, 각 집단의 회귀식의 기울기에 대한 유의도를 검증하였다.

\section{Results}

\section{상관분석}

\section{남자 청소년}

청소년의 성에 따른 변수 간 상관관계를 살펴보기 위해 남자 청소년과 여자 청소년 각각의 Pearson의 적률상관계수를 산출 하였다(Table 1). 먼저 남자 청소년의 경우를 구체적으로 살펴 보면 다음과 같다. 첫째, 집단의 도덕적 이탈은 또래동조성 $(r=$ $.18, p<.05)$ 과 유의한 정적 상관을 보였다. 즉, 개인이 집단의 도덕적 이탈의 정도를 높게 인식할수록 또래동조성이 높았다. 둘째, 집단의 도덕적 이탈은 또래괴롭힘 방관 행동 $(r=.26, p<$ $.01)$ 과 유의미한 정적 상관을, 방어 행동과 부적 상관 $(r=-.17$, $p<.05$ )을 보였다. 즉, 개인이 집단의 도덕적 이탈의 정도를 높 게 지각할수록 또래괴롭힘 상황에서 방관 행동의 정도가 높고 방어 행동은 낮았다. 셋째, 또래동조성은 방관 행동 $(r=.28, p<$ $.01)$ 과 유의미한 정적 상관을, 방어 행동과는 부적 상관 $(r=-.16$, $p<.05)$ 을 보였다. 즉, 개인의 또래동조성이 높을수록 방관 행 동의 정도가 높았지만 방어 행동은 낮았다. 마지막으로, 또래 괴롭힘 방관 행동은 방어 행동과 부적 상관 $(r=-.49, p<.01)$ 을 보였다. 즉, 방관 행동의 정도가 높을수록 방어 행동은 낮았다.

\section{여자 청소년}

여자 청소년의 변인 간 상관관계를 구체적으로 살펴보면 다음 과 같다(Table 2). 첫째, 집단의 도덕적 이탈은 남자 청소년과 는 달리 또래동조성, 또래괴롭힘 방관 및 방어 행동과 통계적 으로 유의한 상관을 보이지 않았다. 
Table 1

Correlations Between the Variables

\begin{tabular}{lllllll}
\hline & 1 & 2 & 3 & 4 & $M_{\text {여 }}$ & $S D$ 여 \\
\hline 1. Collective moral disengagement & - & .04 & .14 & -.00 & 2.34 & 0.65 \\
2. Peer conformity & $.18^{*}$ & - & $.39^{* *}$ & $-.32^{* *}$ & 2.34 & 0.50 \\
3. Bystanding behavior & $.26^{* *}$ & $.28^{* *}$ & - & $-.47^{* *}$ & 2.05 & 0.71 \\
4. Defending behavior & $-.17^{*}$ & $-.16^{*}$ & $-.49^{* *}$ & - & 2.46 & 0.55 \\
$M_{\text {남 }}$ & 2.41 & 2.31 & 1.98 & 2.44 & & \\
$S D_{\text {남 }}$ & 0.57 & 0.48 & 0.75 & 0.60 & & \\
\hline
\end{tabular}

Note. $N=314$. 대각선 아래 = 남자 청소년 $(n=167)$; 대각선 위 $=$ 여자 청소년 $(n=147)$.

${ }^{*} p<.05 .{ }^{* *} p<.01$.

둘째, 또래동조성은 방관 행동 $(r=.39, p<.01)$ 과 유의한 정 적 상관을, 방어 행동과는 부적 상관 $(r=-.32, p<.01)$ 을 보였다. 즉, 개인의 또래동조성이 높을수록 방관 행동의 정도가 높았 지만 방어 행동은 낮았다. 마지막으로, 또래괴롭힘 방관행동 은 방어 행동과 부적 상관 $(r=-.47, p<.01)$ 을 보였다. 즉, 방관 행동의 정도가 높을수록 방어 행동은 낮았다.

\section{집단의 도덕적 이탈이 남녀 청소년의 또래괴 롭힘 방관 및 방어 행동에 미치는 영향에 대 한 또래동조성의 조절효과}

집단의 도덕적 이탈이 남녀 청소년의 또래괴롭힘 방관 및 방 어 행동에 미치는 영향을 또래동조성이 조절하는지를 살펴보 기 위하여 위계적 회귀분석을 실시하였다.

조절효과 분석은 다음과 같은 절차로 이루어졌다. 먼저 다 중공선성을 감소시키기 위해 독립변인인 남녀 청소년의 집단 의 도덕적 이탈과 조절변인인 또래동조성을 중심화하였다. 중 심화한 독립변인과 조절변인을 곱하여 상호작용항을 산출하 였다. 위계적 회귀분석을 실시하여 1 단계에는 독립변인과 조 절변인을 투입하였고, 2단계에는 상호작용항을 추가로 투입 하였다. 조절효과가 유의할 경우 회귀식을 사용하여 그래프 를 도식화하였고, 유의한 상호작용을 구체적으로 살펴보기 위하여 1 차적으로는 독립변인과 조절변인을 평균을 중심으 로 $\pm 1 S D$ (상, 하) 집단으로 구분한 뒤, 두 변인의 관계가 조절 변인에 따라 차이가 있는지 사후검정(post-hoc)을 실시하였다 (Aiken \& West, 1991). 그러나 조절효과가 유의미하게 나타났 지만, 각 집단 모두 회귀식의 기울기가 유의미하지 않을 경우 에는 추가적으로 $\pm 2 S D$ (상, 하)집단으로 나눈 후, 각 집단의 회 귀식의 기울기에 대한 유의도를 검증하였다. 조절효과가 유의 하지 않을 경우에는 주효과만을 분석하였다.
집단의 도덕적 이탈이 남자 청소년의 또래괴롭 힘 방관 및 방어 행동에 미치는 영향에 대한 또 래동조성의 조절효과

집단의 도덕적 이탈이 남자 청소년의 또래괴롭힘 방관 및 방 어 행동에 미치는 영향을 또래동조성이 조절하는지를 살펴보 기 위하여 위계적 회귀분석을 실시하였다(Table 2). 1 단계와 2 단계의 위계적 중다회귀분석의 기본 조건을 충족하는지 알아 보기 위해 또래괴롭힘 방관 및 방어 행동의 Durbin-Watson 지 수와 VIF값을 구했다. 그 결과, Durbin-Watson 지수는 방관 행 동은 1.82 , 방어 행동은 1.99 로 2에 가까워 잔차 간 자기상관이 없는 것으로 볼 수 있으며, 방관 행동과 방어 행동의 VIF값은 $1.04-1.07$ 로 10 보다 현저히 작아 다중공선성의 문제가 없는 것으로 판단하였다.

먼저, 집단의 도덕적 이탈이 남자 청소년의 방관 행동에 미치 는 영향을 또래동조성이 조절하는지 살펴보았다. 그 결과 조절 효과가 유의하지 않았다. 주효과를 분석한 결과, 집단의 도덕적 이탈 $(\beta=.21, p<.01)$ 과 또래동조성 $(\beta=.24, p<.01)$ 이 방관 행동 에 정적인 영향을 미치는 것으로 나타났다. 즉, 개인이 속한 집 단이 도덕적 이탈을 많이 할수록, 또래에 동조하는 성향이 높을 수록 방관 행동이 증가한 것이다. 남자 청소년의 집단의 도덕적 이탈과 또래동조성은 함께 방관 행동을 $12 \%$ 설명하였다.

다음으로 집단의 도덕적 이탈이 남자 청소년의 방어 행동 에 미치는 영향을 또래동조성이 조절하는지를 살펴본 결과, 남자 청소년의 집단의 도덕적 이탈이 방어 행동에 미치는 영 향은 또래동조성에 의해 조절되었다 $(\beta=-.16, p<.05) .1$ 단계 에서 집단의 도덕적 이탈과 또래동조성은 방어 행동의 분산 을 $4 \%$ 설명하였고 2 단계에서 집단의 도덕적 이탈과 또래동조 성의 상호작용항을 추가로 투입한 결과, 두 변인의 상호작용 항의 설명력이 $3 \%$ 가 추가되어 $\left(\Delta R^{2}=.03, p<.05\right)$ 방어 행동을 
Table 2

Moderating Effect of Peer Conformity in Relationship Between Collective Moral Disengagement and Bystanding and Defending Behavior in Boys

\begin{tabular}{|c|c|c|c|c|c|c|}
\hline & & $B$ & $\beta$ & $F\left(d f_{1}, d f_{2}\right)$ & $R^{2}$ & $\Delta R^{2}$ \\
\hline \multirow[t]{3}{*}{ Bystanding behavior } & Collective moral disengagement (A) & .28 & $.21^{* *}$ & $11.42^{* * *}(2,164)$ & .12 & \\
\hline & Peer conformity (B) & .38 & $.24^{* *}$ & & & \\
\hline & $\mathrm{A} \times \mathrm{B}$ & .26 & .09 & $8.09^{* * *}(3,163)$ & .13 & .01 \\
\hline \multirow[t]{3}{*}{ Defending behavior } & Collective moral disengagement (A) & -.15 & -.14 & $3.76^{*}(2,164)$ & .04 & \\
\hline & Peer conformity (B) & -.16 & -.13 & & & \\
\hline & $\mathrm{A} \times \mathrm{B}$ & -.34 & $-.16^{*}$ & $4.01^{* *}(3,163)$ & .07 & $.03^{*}$ \\
\hline
\end{tabular}

Note. $N=167$.

${ }^{*} p<.05 .{ }^{* *} p<.01{ }^{* * *} p<.001$.

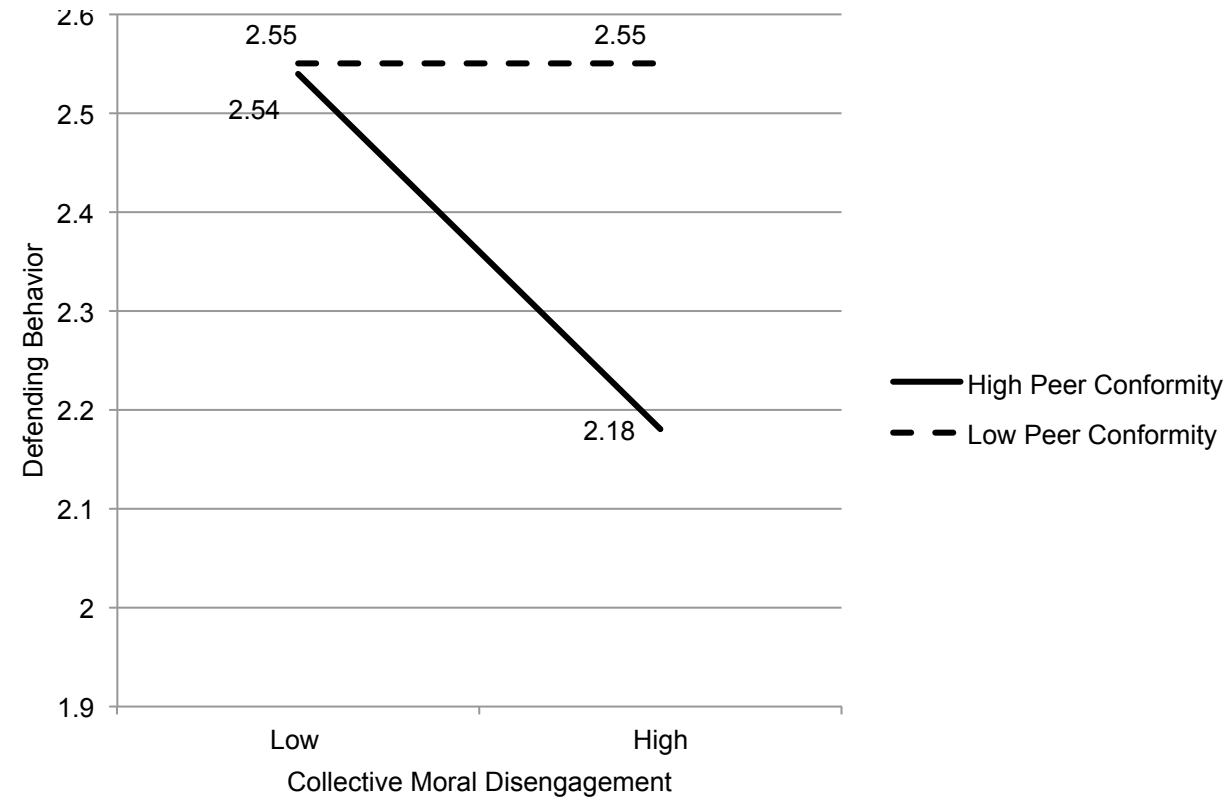

Figure 1. Boys' peer conformity as a moderator in the relationship between collective moral disengagement and detending behavior.

총 $7 \%$ 설명하였다. 유의한 상호작용을 구체적으로 살펴보기 위하여 Aiken과 West (1991)가 제안한 방법을 따라 사후검정 을 실시한 결과(Figure 1$)$, 남자 청소년 $(n=167)$ 중 또래동조성 이 높은 남자 청소년 $(n=96)$ 은 집단의 도덕적 이탈의 정도가 높을수록 방어 행동을 적게 보였지만 $(\beta=-.30, p<.01)$, 또래동 조성이 낮은 남자 청소년 $(n=71)$ 의 경우 집단의 도덕적 이탈 이 방어 행동에 미치는 영향은 유의하지 않았다.

집단의 도덕적 이탈이 여자 청소년의 또래괴롭 힘 방관 및 방어 행동에 미치는 영향에 대한 또 래동조성의 조절효과

집단의 도덕적 이탈이 여자 청소년의 또래괴롭힘 방관 및 방
어 행동에 미치는 영향을 또래동조성이 조절하는지를 살펴보 기 위하여 위계적 회귀분석을 실시하였다(Table 3). 1단계와 2 단계의 위계적 중다회귀분석의 기본 조건을 충족하는지 알아 보기 위해 또래괴롭힘 방관 및 방어 행동의 Durbin-Watson 지 수와 VIF값을 구했다. 그 결과, Durbin-Watson 지수는 방관 행 동은 1.50 , 방어 행동은 1.65 로 2 에 가까워 잔차 간 자기상관이 없는 것으로 볼 수 있으며, VIF값은 방관 행동과 방어 행동 모 두 $1.00 \sim 1.01$ 로 10 보다 현저히 작아 다중공선성의 문제가 없 는 것으로 판단하였다.

먼저, 집단의 도덕적 이탈이 여자 청소년의 방관 행동에 미 치는 영향을 또래동성이 조절하는지 살펴보았다. 그 결과 유 의한 조절효과는 나타나지 않았다. 주효과를 분석한 결과, 또 래동조성이 방관행동에 정적인 영향을 미치는 것으로 나타났 
Table 3

Moderating Effect of Peer Conformity in Relationship Between Collective Moral disengagement and Bystanding and Defending Behavior in Girls

\begin{tabular}{|c|c|c|c|c|c|c|}
\hline & & $B$ & $\beta$ & $F\left(d f_{1}, d f_{2}\right)$ & $R^{2}$ & $\Delta R^{2}$ \\
\hline \multirow[t]{3}{*}{ Bystanding behavior } & Collective moral disengagement (A) & .13 & .12 & $14.40^{* * *}(2,144)$ & .17 & \\
\hline & Peer conformity (B) & .55 & $.39^{* * *}$ & & & \\
\hline & $\mathrm{A} \times \mathrm{B}$ & -.08 & -.04 & $9.62^{* * *}(3,143)$ & .17 & .00 \\
\hline \multirow[t]{3}{*}{ Defending behavior } & Collective moral disengagement (A) & .01 & .01 & $7.92^{* *}(2,144)$ & .10 & \\
\hline & Peer conformity (B) & -.35 & $-.32^{* * *}$ & & & \\
\hline & $\mathrm{A} \times \mathrm{B}$ & -.32 & $-.18^{*}$ & $7.24^{* * *}(3,143)$ & .13 & $.03^{*}$ \\
\hline
\end{tabular}

Note. $N=147$.

${ }^{*} p<.05 .{ }^{* *} p<.01 .{ }^{* * *} p<.001$.

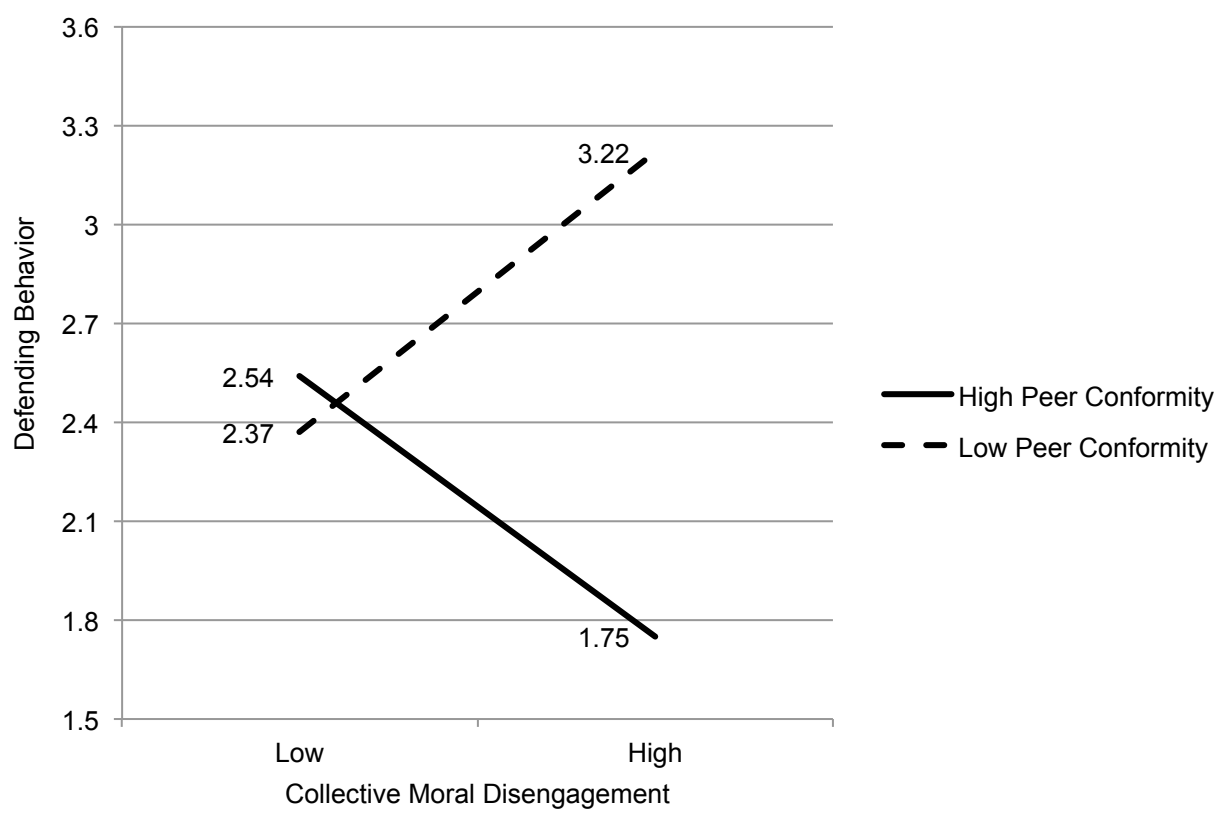

Figure 2. Girls' peer conformity as a moderator in the relationship between collective moral disengagement and defending behavior.

다 $(\beta=.39, p<.001)$. 즉, 또래에 동조하는 성향이 높을수록 방 관 행동이 증가한다는 것이다. 여자 청소년의 집단의 도덕적 이탈과 또래동조성은 함께 방관 행동을 $17 \%$ 설명하였다.

다음으로, 집단의 도덕적 이탈이 여자 청소년의 방어 행동 에 미치는 영향을 또래동조성이 조절하는지를 살펴본 결과, 집단의 도덕적 이탈이 여자 청소년의 방어 행동에 미치는 영 향은 또래동조성에 의해 조절되었다 $(\beta=-.18, p<.05) .1$ 단계 에서 집단의 도덕적 이탈과 또래동조성은 방어 행동의 분산을 $10 \%$ 설명하였고 2 단계에서 집단의 도덕적 이탈과 또래동조 성의 상호작용항을 추가로 투입한 결과, 두 변인의 상호작용 항의 설명력이 $3 \%$ 가 추가되어 $\left(\Delta R^{2}=.03, p<.05\right)$ 방어 행동을 총 $13 \%$ 설명하였다. 독립변인과 조절변인을 평균을 중심으
로 $\pm 1 S D$ (상, 하) 집단으로 구분한 뒤, 두 변인의 관계가 조절 변인에 따라 차이가 있는지 사후검정(post-hoc)을 실시하였다 (Aiken \& West, 1991). 그 결과, 또래동조성이 높은 집단과 낮 은 집단 모두 집단의 도덕적 이탈이 방어 행동에 유의한 영향 을 미치지 않았다. 그러나 집단의 도덕적 이탈과 또래동조성 을 평균을 중심으로 $\pm 2 S D$ (상, 하) 집단으로 구분한 뒤, 사후검 정(post-hoc)을 실시하였을 때는(Aiken \& West, 1991), 또래동 조성이 높은 집단과 낮은 집단 모두 집단의 도덕적 이탈이 방 어 행동에 유의한 영향을 미쳤다(Figure 2). 즉, 여자 청소년 ( $n$ $=147)$ 중 또래동조성이 높은 여자 청소년 $(n=76)$ 은 집단의 도 덕적 이탈의 정도가 높을수록 방어 행동을 적게 보였지만 $(\beta=$ $-.36, p<.05)$, 또래동조성이 낮은 여자 청소년 $(n=71)$ 은 집단 
의 도덕적 이탈의 정도가 높을수록 방어 행동을 높게 보였다 $(\beta=.39, p<.05)$.

\section{Discussion}

본 연구는 경기도와 인천광역시에 소재한 중학교에 재학 중인 남녀 청소년을 대상으로 개인의 또래동조성이 집단의 도덕적 이탈과 또래괴롭힘 방관 및 방어 행동간 관계를 조절하는지 성을 나누어 살펴보았다. 다음은 본 연구의 결과를 요약하고 논의한 것이다.

첫째, 남자 청소년의 또래동조성이 집단의 도덕적 이탈과 또래괴롭힘 방관 및 방어 행동간 관계를 조절하는지 살펴보 았다. 먼저, 남학생의 또래동조성은 집단의 도덕적 이탈과 또 래괴롭힘 방관 행동간 관계를 조절하지 못하였다. 그러나 주 효과를 분석해보았을 때, 여학생과는 달리 남학생의 경우 집 단의 도덕적 이탈이 방관 행동을 정적으로 예측하였다. 이러 한 결과는 남학생이 여학생보다 자신이 주로 어울리는 소집 단의 인식에 더 큰 영향을 받기보다 전체의 또래압력에 영향 을 받기 때문에(E.-A. Kim \& Lee, 2011), 학급 집단이 도덕적으 로 얼마나 이탈되었는지가 그들의 방관 행동을 정적으로 예측 한 것으로 보인다. 이는 집단의 도덕적 이탈 정도가 높다고 인 지할수록 방관 행동을 많이 한다는 선행연구의 결과를 지지 한다(Gini et al., 2015; Thornberg et al., 2017). 같은 학급에 속 한 또래들의 도덕적 이탈의 정도를 높게 인지할 경우, 피해자 를 도와주었다가 자신 또한 피해자가 될 수 있을 것 같은 불안 감과 두려움(Pozzoli \& Gini, 2010), 그리고 괴롭힘 상황에서 자 신이 피해자를 방어하고자 하여도 이것이 실제로 효과를 보일 지에 대한 의문으로(Thornberg et al., 2017) 방관하는 행동이 증 가했을 것으로 예상된다. 또한 집단따돌림에 허용적인 집단규 범이 존재한다고 개인이 인지할 때, 공감능력이 높은 학생들도 피해자를 방어하는 데 소극적인 태도를 보였으므로(Pöyhönen, Juveonen, \& Salmivalli, 2010), 친사회적 행동을 예측하는 개인내 적요인을 가지고 있는 남학생이라도 집단의 도덕적 이탈의 수 준을 높게 인지할 경우 방관 행동을 많이 할 것으로 추정된다.

이는 학급 내 학생들이 괴롭힘에 대하여 허용적이라고 인 지한 학생의 경우 학급 구성원들로부터 배척당하지 않기 위한 안전장치로 괴롭힘을 방관한다(Chun, 2019)는 선행연구 결과 와도 맥을 함께 한다. 따라서 남학생들에게는 학급의 구성원 들이 도덕적으로 이탈되어있지 않다는 환경을 조성하여, 자신 의 방어 행동이 또래들에게 지지받는 긍정적인 결과를 가져올
것이라고 생각하게 만듦으로써 방어 행동을 촉진하는 것이 중 요할 것으로 판단된다. 또한 전체 학급을 한 단위로 목표를 설 정하는 것이 더욱 효율적인 또래괴롭힘 예방 및 개입으로 작 용할 수 있을 것이다.

한편, 남학생의 방관 행동의 또 다른 주효과를 살펴보면 또 래동조성은 방관 행동에 정적인 영향을 미쳤다. 이는 또래에 동조하는 성향이 높은 학생은 방관 행동을 많이 하며, 또래동 조성향이 낮은 학생은 방관 행동을 적게 한다는 것을 의미한 다. 또래동조성이 높은 청소년은 자신의 도덕추론에 대한 확신 을 가지고 있더라도 집단의 행동을 따르는 경향이 있어(H.-L. Cho, 2002; B.-E. Kim \& Choi, 2016), 주변 또래가 피해자를 돕 지 않는 태도에 영향을 받아 괴롭힘을 보고도 모른 체 했을 가 능성이 높다. 또한 또래에 동조하는 성향이 낮은 청소년은 집 단이 지닌 가치와 행동이 자신의 신념과 일치하지 않을 때에 자신의 기준에 따라 행동하기 때문에(Chon, Lee, Yoo, \& Lee, 2004), 괴롭힘 상황에서 피해자를 방관하는 행동이 감소했을 것으로 추정된다. 이러한 결과는 또래동조성이 또래괴롭힘의 방관 행동에 유의한 정적 영향을 미친 여러 선행연구들과 일치 하며(Y. Cho \& Chung, 2009; J.-H. Chung \& Oh, 2018; Jeong \& Lee, 2016), 발달 시기상 청소년 중기에 가장 높게 나타나는 또 래동조성(Berndt, 1979)의 영향력이 유효함을 입증하였다.

다음으로, 남학생의 또래동조성은 집단의 도덕적 이탈과 또래괴롭힘 방관 행동간 관계를 유의미하게 조절하지 못하였 지만, 방어 행동간 관계에서는 조절효과가 유의하였다. 특히 이는 여학생보다 남학생에게서 두드러지게 나타났다. 청소년 들은 청소년기 발달 특성상 또래와의 원만한 관계를 유지하 는 것을 중요하게 여기며, 또래와 다르게 행동하기를 주저하 는 경향을 보인다(Chun, 2019). 이러한 또래동조성이 높을 경 우 개인의 도덕적 판단이 약화되어, 개인적 신념이 또래집단 과 일치하지 않더라도 집단의 행동에 동조하도록 한다(Chon et al., 2004). 따라서 이들은 자신의 도덕성이 올바르게 발달되 었음에도 불구하고 학급 또래들의 도덕적 이탈 수준이 높다 고 인지할 경우, 이를 정당화시켜 주변 또래들의 부정적인 행 동들을 무비판적으로 모방했을 것으로 판단된다. 또한 우리나 라 청소년들은 1 년간 동일한 학급친구들과 장시간 생활을 공 유하며 지속적인 관계를 유지하기 때문에 서로를 더욱 의식하 는 경향이 있어(Chun, 2019), 학급 학생들의 도덕적 이탈 정도 는 또래동조성과 마찬가지로 괴롭힘 상황에서 자신의 행동 기 준으로서 작용될 가능성이 높다. 도덕적 기준이 외부의 자극 으로부터 학습되어 내부의 자율적인 요인으로 내면화되는 도 덕성 발달의 과정을 고려하면(Bandura et al., 1996), 집단이 도 
덕적으로 많이 이탈되었다고 인지할 경우, 또래동조성이 높은 개인은 이를 더욱 내면화 시켜 괴롭힘 상황에서 피해자를 보 호하고자 하는 행동이 약화되는 것으로 해석된다.

둘째, 여자 청소년의 또래동조성이 집단의 도덕적 이탈과 또래괴롭힘 방관 및 방어 행동간 관계를 조절하는지 살펴보았 다. 그 결과 남학생과 마찬가지로 방관 행동에의 조절효과는 유의하지 않았으나, 방어 행동에는 유의미한 조절효과를 보였 다. 남학생과 비교하여 좀 더 주목하여볼 점은, 여학생의 경우 개인적 특성인 또래의 규범에 순응하거나 동조하는 심리적 경 향은 방관 및 방어 행동에 영향을 미쳤으나, 맥락적 특성인 집 단의 도덕적 이탈은 방관 행동과 방어 행동을 독립적으로 예 측하지 못하였다는 것이다. 이처럼 여학생에게 있어서 집단의 도덕적 이탈이 방관 및 방어 행동을 설명하지 못한 이유에 대 해서는 다음과 같은 가능성을 고려해볼 수 있다.

먼저, 여학생은 남학생보다 학급 집단 내에서 더 작은 내집 단을 구성하고 강력한 연대감을 공유하여(Mouttapa, Valenti, Gallaher, Rohrbach, \& Unger, 2004), 또래괴롭힘 상황에서도 자 신의 친한 친구들의 행동으로 바꾸는 경향이 많은 것으로 알 려졌다(Salmivalli et al., 1996). 따라서 여학생에게는 또래괴롭 힘에 대해 학급 전체의 친구들이 도덕적으로 얼마나 이탈되었 는지에 대한 인식보다는 자신이 속해있는 소집단에 대한 동조 성향이 더 큰 영향을 미칠 수 있다는 것이다. 또한 실제로 몇 몇 선행연구에서는 학급 내에서 자신이 친밀하다고 생각하 는 또래들로부터 느끼는 압력과 친구가 아닌 이들로부터 느 끼는 압력은 다를 수 있다는 점(Mouttapa et al., 2004), 그리고 여학생의 경우 자신의 친밀한 친구인지 여부에 따라 정서적 결속력과 사적인 부분에 관여하는 정도가 크게 다르다는 점 (Maccoby, 1998)을 제안하여 이러한 가능성을 뒷받침하였다. 따라서 여학생은 남학생과 달리 학급 전체의 도덕적 이탈의 정도가 방관 및 방어 행동을 예측하지 못하였으므로, 또래괴 롭힘 개입 방안으로 개인의 또래동조성향에 보다 주의를 기울 일 필요가 있을 것으로 사료된다.

한편, 여학생의 또래동조성은 집단의 도덕적 이탈과 방어 행동간 관계를 유의미하게 조절하였다. 특히 남학생은 또래동 조성이 낮은 집단에서만 이러한 조절효과가 유의하였으나, 여 학생은 또래동조성이 낮은 집단과 높은 집단 모두에게서 또래 동조성의 조절효과가 유의미하였다. 또한 남학생과 달리 여학 생의 또래동조성은 집단의 도덕적 이탈과 상관관계가 나타나 지 않았음에도 불구하고, 여학생의 또래동조성과 집단의 도덕 적 이탈이 상호작용하여 방어 행동을 설명하는 크기는 남학생 보다 더욱 크게 나타났다. 이는 발달 시기상 청소년 중기에 가
장 높게 나타나는 또래동조성(Berndt, 1979)의 영향력이 여학 생에게서 더 높게 나타난 선행연구와 맥을 함께한다(Y. Cho \& Chung, 2009). 따라서 또래동조성이 높은 여학생의 경우 또래 동조성이 높은 남학생보다 학급 분위기가 도덕적으로 부정적 이라고 인식될 때 더욱 영향을 받는 집단이므로, 학급 내의 도 덕적 이탈 수준을 낮출 수 있는 도덕성 함양 교육을 통해 또래 괴롭힘에 가담 및 방관하는 행동에 대한 부정적 인식이 강하 게 조성되는 것이 또래괴롭힘을 예방하는데 중요할 것으로 예 상된다.

종합하면, 남녀 청소년의 또래동조성은 개인이 인지한 집단 의 도덕적 이탈과 또래괴롭힘 상황에서의 방관 행동과의 관계 는 조절하지 못하였지만, 방어 행동과의 관계는 유의하게 조 절하였다. 이와 같은 본 연구의 결과는 높은 수준의 집단의 도 덕적 이탈이 방어 행동의 위험요인으로 작용할 때, 높은 또래 동조성은 이러한 부정적 영향력을 더욱 강화하는 부정적 지표 로 작용하고 낮은 또래동조성은 이러한 부정적 영향력을 완화 시켜주는 긍정적 지표로 작용한다는 것을 의미한다. 이처럼 학 급 집단의 도덕적 이탈 정도와 개인이 지닌 또래동조성이 상호 작용하여 또래괴롭힘 방어 행동을 예측한다는 점을 고려할 때, 괴롭힘 주변인들이 피해 상황을 보고도 모른척하지 않고 적극 적으로 가해 행동을 중재하려고 노력하도록 교실 내 문화를 바 꾸기 위해서는, 학급 구성원들이 속한 전체 집단의 도덕적 규 준을 올바르게 심어주고 올바른 도덕적 판단을 길러주는 것이 중요하다. 뿐만 아니라, 맹목적인 친구지지를 줄이면서 그들이 또래괴롭힘 상황을 방관하지 않고 자신의 가치에 따라 행동할 수 있도록 인지적인 신념을 발달시켜주는 것이 중요한 과제임 을 알 수 있다. 한편, 방관 행동의 경우 남학생의 집단의 도덕적 이탈과 또래동조성의 주효과가 있었고, 여학생의 또래동조성 의 주효과가 나타났으므로 이러한 시사점은 방관 행동을 예방 하는데도 긍정적인 역할을 할 수 있을 것으로 추정된다.

본 연구의 제한점과 후속연구를 위한 제언은 다음과 같다. 첫째, 본 연구에서 선택한 집단의 도덕적 이탈과 또래동조성 의 상호작용 효과는 또래괴롭힘 방관 행동을 설명하지 못하였 다. 방관 행동을 피해자 방어 행동으로 변화시킬 수 있도록 만 드는 기제에 관하여 충분한 사례수를 수집하여 추후 연구에서 탐색해볼 필요성을 제안한다. 둘째, 또래괴롭힘 방관 및 방어 행동을 정확히 측정하는데 있어 자기보고식에 한정하지 않고, 또래보고, 교사보고 등을 활용하여 측정방식을 다양화할 필요 가 있다. 실제 또래괴롭힘 주변인 역할 행동에 관한 국외의 선 행연구에서 또래보고와 자기보고 모두 유사한 패턴을 유지하 여 자기보고로 측정하여도 무관함이 제시되었지만(Caroline 
\& Bukowski, 2015), 한편으로는 자기보고식 척도가 사회적 바 람직성이 개입될 가능성도 있기 때문이다(Shin \& Kang, 2014). 셋째, 본 연구에서는 또래동조성의 하위요인을 합산하여 조절 효과를 살펴보았으나, 또래괴롭힘이라는 상황을 고려하여 보 았을 때 중립적 동조성과 반사회적 동조성이라는 두 가지 동 조성의 조절 효과가 다르게 나타날 가능성이 있으므로 추후 연구에서는 이러한 두 영역의 동조성을 분리하여 효과를 비 교해볼 것을 제안한다. 넷째, 후속 연구에서는 집단 차원의 도 덕적 이탈의 효과를 보다 정확하게 반영하기 위해서 Nested Model로 학급 차원과 개인 차원을 분리해서 측정하고 HLM과 같은 분석 방법을 적용할 필요가 있다.

그러나 위와 같은 제한점에도 불구하고 본 연구는 다음과 같은 의의를 지닌다. 첫째, 본 연구는 청소년기의 또래괴롭힘 주변인 개입을 구체적으로 파악하기 위하여 이들의 발달적 특 성을 반영한 또래동조성과 맥락 특성을 지닌 집단의 도덕적 이탈을 함께 연구했다는 점에서 의의가 있다. 여러 선행연구 들에서 개인내적 변인에 더하여 성과 환경적 변인을 함께 고 려하여 보다 객관적인 이해가 이루어져야함을 제시한 만큼, 본 연구는 성과 또래동조성이라는 개인적 변인과 더불어 집단 의 도덕적 이탈이라는 환경적 변인을 모두 고려했다는 점에서 가치가 있다. 둘째, 본 연구는 또래괴롭힘 상황에서의 주변인 역할 행동과 관련된 변인을 탐색함으로써 또래괴롭힘 주변인 역할 행동을 위한 경험적 연구 자료를 마련하였다. 본 연구는 개인이 인지한 집단의 도덕적 이탈의 정도가 주변인 역할 행 동 중 가장 모범적인 행동으로 주목되어지는 방어 행동에 미 치는 영향을 이해하기 위해 또래동조성 수준을 고려하여야 함 을 밝혔다. 이에 따라, 또래괴롭힘 예방 프로그램과 상담에서 청소년이 속한 학급의 도덕적 이탈 정도와 개인의 또래동조성 수준을 함께 고려하여 접근한다면 괴롭힘 상황에서 피해자를 보호하는 행동을 증가시킬 수 있는 개입방안을 이끌어낼 수 있을 것으로 사료된다. 결국 본 연구는 그 동안의 개입의 중점 이 되었던 개인 중심의 개입과 예방적 접근에 더하여 또래동 조성과 함께 개인이 인지하는 집단의 도덕성을 보다 긍정적으 로 변화시켜야 한다는 새로운 개입 방향의 근거를 제공하였다 는데 의의가 있다.

\section{Conflict of Interest}

No potential conflict of interest relevant to this article was reported.

\section{References}

\section{In English}

Aiken, L. S., \& West, S. G. (1991). Multiple regression: Testing and interpreting interactions. Thousand Oaks, CA: Sage Publications.

Almeida, A., Correia, I., \& Marinho, S. (2010). Moral Disengagement, normative beliefs of peer group, and attitudes regarding roles in bullying. Journal of School Violence, 9(1), 23-36. doi:10.1080/15388220903185639

Bandura, A., Barbarnelli, C., Caprara, G. V., \& Pastorelli, C. (1996). Mechanisms of moral disengagement in the exercise of moral agency. Journal of Personality and Social Psychology, 71(2), 364-374. doi:10.1037/0022-3514. 71.2.364

Baron, R. M., \& Kenny, D. A. (1986). The moderator-mediator variable distinction in social psychological research: Conceptual, strategic, and statistical considerations. Journal of Personality and Social Psychology, 51(6), 1173-1182. doi:10.1037/0022-3514.51.6.1173

Berndt, T. J. (1979). Developmental changes in conformity to peers and parents. Developmental Psychology, 15(6), 608-616. doi:10.1037/0012-1649.15.6.608

Boulton, M. J., Trueman, M., \& Flemington, I. (2002). Associations between secondary school pupils' definitions of bullying, attitudes towards bullying, and tendencies to engage in bullying: Age and sex differences. Educational Studies, 28(4), 353-370. doi:10.1080/0305569022000042390

Caroline, D., \& Bukowski, W. M. (2015). A longitudinal study of the associations between moral disengagement and active defending versus passive bystanding during bullying situations. Merrill-Palmer Quarterly, 61(1), 144-172. doi:10.13110/merrpalmquar1982.61.1.0144

Cowie, H. (2014). Understanding the role of bystanders and peer support in school bullying. International Journal of Emotional Education, 6(1), 26-32. Retrieved from ERIC database. (EJ1085728)

Gini, G., Albiero, P., Benelli, B., \& Altoè, G. (2008). Determinants of adolescents' active defending and passive bystanding behavior in bullying. Journal of Adolescences, 31(1), 93-105. doi:10.1016/j.adolescence.2007.05.002

Gini, G., Pozzoli, T., \& Bussey, K. (2014). Collective moral disengagement: Initial validation of a scale for adolescents. European Journal of Developmental Psychology, 11(3), 386395. doi:10.1080/17405629.2013.851024

Gini, G., Pozzoli, T., \& Bussey, K. (2015). The role of individual and collective moral disengagement in peer aggression and bystanding: A multilevel analysis. Journal of Abnormal Child Psychology, 43, 441-452. doi:10.1007/s10802-014-9920-7 
Griffin, R. S., \& Gross, A. M. (2004). Childhood bullying: Current empirical findings and future directions for research. Aggression and Violent Behavior, 9(4), 379-400. doi:10.1016/ S1359-1789(03)00033-8

Hawker, D. S. J., \& Boulton, M. J. (2000). Twenty years' research on peer victimization and psychosocial maladjustment: A meta-analytic review of cross-sectional studies. The Journal of Child Psychology and Psychiatry Allied Disciplines, 41(4), 441-455. doi:10.1111/1469-7610.00629

Kimberley, R. A., \& Bussey, K. (2017). Individual and collective moral influences on intervention in cyberbullying. Computers in Human Behavior, 74, 7-15. doi:10.1016/j.chb.2017.04.019

Kollerová, L., Soukup, P., \& Gini, G. (2018). Classroom collective moral disengagement scale: Validation in Czech adolescents. European Journal of Developmental Psychology, 15(2), 184191. doi:10.1080/17405629.20 17.1292907

Maccoby, E. E. (1998). The two sexes: Growing up apart, coming together. Cambridge, MA: Havard University Press.

Mazzone, A., Camodeca, M., \& Salmivalli, C. (2016). Interactive effects of guilt and moral disengagement on bullying, defending and outsider behavior. Journal of Moral Education, 45(4), 419-432. doi:10.1080/03057240.2016.12 16399

Mouttapa, M., Valenti, T., Gallaher, P., Rohrbach, L. A., \& Unger, J. B. (2004). Social network predictors of bullying and victimization. Adolescence, 39(154), 315-335.

Nickerson, A. B., Mele, D., \& Princiotta, D. (2008). Attachment and empathy as predictors of roles as defenders or outsiders in bullying interactions. Journal of School Psychology, 46(6), 687-703. doi:10.1016/j.jsp.2008.06.002

O’Connell, P., Pepler, D., \& Craig, W. (1999). Peer involvement in bullying: Insights and challenges for intervention. Journal of Adolescence, 22(4), 437-452. doi:10.1006/jado.1999.0238

Olweus, D. (1993). Victimization by peers: Antecedents and longterm outcomes. In K. H. Rubin \& J. B. Asendorpf (Eds.), Social withdrawal, inhibition, and shyness in childhood (pp. 315-341). Mahwah, NJ: Erlbaum.

Pöyhönen, V., Juveonen, J., \& Salmivalli, C. (2010). What does it take to stand up for the victim of bullying? The interplay between personal and social factors. Merrill-Palmer Quarterly, 56(2), 143-163. doi:10.1353/mpq.0.0046

Pozzoli, T., \& Gini, G. (2010). Active defending and passive bystanding behavior in bullying: The role of personal characteristics and perceived peer pressure. Journal of Abnormal Child Psychology, 38, 815-827. doi:10.1007/s10802-010-9399-9

Pozzoli, T., Gini, G., \& Thornberg, R. (2016). Bullying and defending behavior: The role of explicit moral cognition. Journal of School Psychology, 59, 67-81. doi:10.1016/j.jsp.2016.09.005

Pozzoli, T., Gini, G., \& Vieno, A. (2012). The role of individual correlates and class norms in defending and passive bystanding behavior in bullying: A multilevel analysis. Child Development,
83(6), 1917-1931. doi:10.1111/j.14 67-8624.2012.01831.x

Salmivalli, C., Lagerspetz, K., BjÖrkqvist, K., Österman, K., \& Kaukiainen, A. (1996). Bullying as a group process: Participant roles and their relations to social status within the group. Aggressive Behavior, 22(1), 1-15. doi:10.1002/ (SICI) 1098-2337(1996)22:1<1::AID-AB1>3.0.CO;2-T

Sandstrom, M. J., \& Bartini, M. (2010). Do perceptions of discrepancy between self and group norms contribute to peer harassment at school? Basic and Applied Social Psychology, 32(3), 217-225. doi:10.1080/01973533. 2010.495645

Santor, D. A., Messervey, D., \& Kusumakar, V. (2000). Measuring peer pressure, popularity, and conformity in adolescent boys and girls: Predicting school performance, sexual attitudes, and substance abuse. Journal of Youth and Adolescence, 29, 163-182. doi:10.1023/A:1005152515264

Sutton, J., \& Smith, P. K (1999). Bullying as a group process: An adaptation of the participant role approach. Aggressive Behavior, 25(2), 97-111. doi:10.1002/(SICI) 1098-2337 (1999) 25:2<97::AID-AB3>3.0.CO;2-7

Thornberg, R., Wänström, L., \& Pozzoli, T. (2017). Peer victimisation and its relation to class relational climate and class moral disengagement among school children. Educational Psychology, 37(5), 524-536. doi:10.1080/01443 410.2016.1150423

\section{In Korean}

Bang, E. H. (2018). The relationship between teacher support and moral disengagement: The moderating role of bullying participant role (Master's thesis). Retrieved from http:// www.riss.kr/link?id=T14911491

Cho, H.-L. (2002). A study on group-alienation of middle school students. Yonsei Social Welfare Review, 8, 1-26.

Cho, Y., \& Chung, O.-B. (2009). A mediated moderation model of conformative peer bullying in adolescents-Focusing on the influence of peer conformity-. The Korean Journal of Human Development, 16(3), 91-111.

Chon, J.-Y., Lee, E.-K., Yoo, N.-H., \& Lee, K.-H. (2004). A study on the relation between conformity in group bullying and psychological characteristics. The Korean Journal of School Psychology, 1(1), 23-35.

Chun, J. (2019). A study on school bullying in the peer group context. Theory and Research in Citizenship Education, 51(1), 207-238.

Chung, H.-J. (2011). Reciprocal influence between bullying and problem behavior in childhood-Focused on developmental trajectories and predictors-(Doctoral dissertation). Retrieved from http://www.riss.kr/link?id=T1228 1328

Chung, J.-H., \& Oh, I.-S. (2018). The sequential mediating effects 
of peer relationship quality and peer conformity on the relationship between adolescents' empathy and bystander's behavior in peer bullying. Secondary Education Research, 66(2), 575-605.

Jang, H. (2009). Adolescent psychology. Seoul: Parkyoungsa.

Jeong, S., \& Lee, D. (2016). Moderating roles of perceived class norms in the relationship of peer conformity and bystander role behaviors in bullying among middle school students. Korean Education Inquiry, 34(2), 27-45.

Kim, B.-E., \& Choi, S.-M. (2016). The effects of moral reasoning of early adolescents on the bullying: The moderating effects of adolescents peer conformity and the mediating effects of empathy. Korean Journal of Youth Studies, 23(3), $29-52$.

Kim, B. K., \& Han, Y. (2016). Peer conformity and SNS peer-bullying among upper grade elementary school students: The moderating role of moral disengagement. Journal of the Korea Contents Association, 16(9), 339-348.

Kim, E.-A., \& Lee, S. (2011). The roles of empathy, self-efficacy, and beliefs in classroom norm in defending behaviors among middle school students. The Korean Journal of Developmental Psychology, 24(1), 59-77.

Kim, J., \& Kim, J. (2000). The relationship between peer bullying and classroom climates. The Journal of Educational Studies, 31(1), 53-74.

Ministry of Education. (2017). The first survey on school violence. Retrieved from MOE website: https://www.moe.go.kr

Ministry of Education. (2018). 2018nyeon 1cha haggyopoglyeog siltaejosa gyeolgwa [2018년 1차 학교폭력 실태조사 결과]. Retrieved from MOE website: https://www.moe.go.kr

Nam, M.-A., \& Hong, B. (2015). A study of factors affecting the bystanders role in school violence. Journal of the Korean Society of Child Welfare, 50, 109-144.

Seo, M. (2008). Participation in bullying: Bystanders' character- istics and role behaviors. Korean Journal of Child Studies, 29(5), 79-96.

Seo, M. (2013). The influences of moral disengagement and moral emotions on bullying assistant behavior. Korean Journal of Child Studies, 34(6), 123-138. doi:10.5723/ KJCS.2013.34.6.123

Shin, E. K., \& Kang, M. J. (2014). The effect of sex, internal locus of control and empathy on children's conformity behavior in bullying. Korean Journal of Youth Studies, 21(5), 329358.

Sim, H. (2008). Bullying situations: Gender differences in social status and social emotions of participant roles. Korean Journal of Child Studies, 29(3), 191-205.

Song, K., \& Lee, S. (2018). Children's moral reasoning and defending behavior in school bullying: The moderation effects of classroom level characteristics. The Korean Journal of Developmental Psychology, 31(2), 83-103.

Song, J.-Y., \& Oh, I.-S. (2016). Experiential, psychological, and situational factors influencing on bystander's defending tendency in bullying. Korean Journal of Youth Studies, 23(5), 457-478.

\section{ORCID}

$\begin{array}{ll}\text { Ji-won Kim } & \text { http://orcid.org/0000-0002-8091-6750 } \\ \text { Sae-Young Han } & \text { http://orcid.org/0000-0001-8207-5927 }\end{array}$

Received February 29, 2020

Revision received March 26, 2020

Accepted April 8, 2020 